\title{
Reading Performance Profile of Children with Dyslexia in Primary and Secondary School Students
}

\author{
Emine Balcı ${ }^{1} \&$ Aybala Çayır ${ }^{2}$ \\ ${ }^{1}$ Ministry of Education, Ankara, Turkey \\ ${ }^{2}$ Department of Primary School Teaching, Faculty of Education, Aksaray University, Turkey \\ Correspondence: Emine Balc1, Ministry of Education, Ankara, Turkey. E-mail: eminecetinbalci@hotmail.com
}

Received: August 28, 2017

Accepted: September 19, 2017 Online Published: September 21, 2017

doi:10.5539/jel.v7n1p80

URL: https://doi.org/10.5539/jel.v7n1p80

\begin{abstract}
The purpose of the present research was to provide information to the community about the reading subskill profiles of children with dyslexia in primary and secondary school students. 175 children (aged 7-15 yrs) were examined on a varied set of phonological coding, spelling and fluent reading tasks. For this purpose, students' fluent reading were determined using The Informal Reading Inventory. The student's letter recognition and phonetics were measured by the alphabet test. The syllable test was used to measure the learner's ability to read syllables. Results have shown that most of the dyslexic students have the spelling problem (35\%) and fluent reading problem $(51 \%)$. The proportion of students who can only learn letters $(5 \%)$ and students who never learn to read $(7 \%)$ is very small. Results revealed that dyslexic students do not have any significant problems in the phonological coding process but these students at each grade level have problems especially in spelling and fluent reading processes.
\end{abstract}

Keywords: dyslexia, dyslexic, primary school, reading, reading performance, secondary school

\section{Introduction}

Reading does not constitute a skill that occurs naturally in an individual. Rather, it is one of the most difficult and complex skills acquired in human life. Although anyone without a neurological disability can speak, not everyone can read. This is because reading requires more sensitive visual, auditory and mental activities compared to the speaking. Learning to read is a cognitive and linguistic skill, and can usually be acquired through external support. It is linguistic since it is learnt using certain areas of the brain during the processing of language. It is also cognitive for as much as the existing cognitive reserves of the brain are used during learning to read. Therefore, learning to read has a cognitive-linguistic structure (Shaywitz, 2003; Shaywitz, 1998).

Frith (1985) describes this cognitive-linguistic structure of reading in three stages: logographic, alphabetical and orthographic. In the logographic stage, one begins to recognize the shapes of the words that one sees. In alphabetical order, the letter-sound relation is learnt. They use this knowledge whenever they read unfamiliar words. The alphabetical stage is a term where intensive phonological processes are used. In the orthographic stage, however, one does not need phonological translation during reading. The words are not read letter by letter or through spelling; they are rather automatically recognized. Also, since they are orthographically recognized, the words are read faster and the meaning of the word is reached (Frith, 1985).

These stages, which are experienced by successful readers while learning to read, may not be the same for all readers. Among the logographic process, alphabetical process and orthographic process, the individuals with dyslexia are most likely to stumble in the alphabetical stage. Frith states that especially young readers experience problems in phonological processes and, accordingly, have problems in transiting from the alphabetical process to the orthographic process. Those with developmental dyslexia usually spend more time in the acquisition of phonemes and in the development of phonological skills (Balcı \& Çayır, 2017).

On the other hand, Ehri (2005) suggests that children with enough alphabetic skills can read the words more easily, can add any new words that they read to their vocabulary and, thus, can achieve a fluent and automatic reading. This period, referred to as the orthographic process by Frith, includes the accurate, fast and automatic word recognition and reading process which is also necessary for fluent reading. The individuals with dyslexia who hesitate to misspell each sound unit that forms the word, keep themselves under control through slow 
reading, and encounter problems in the orthographic stage even if they pass the alphabetical stage. According to Barton (2002), fluency problems in reading constitute one of the problems that are difficult to solve even in the adulthood of an individual with dyslexia (Ehri, 2005; Barton, 2002).

Knowing the problem into which the students with dyslexia are most likely to stuck during their process of learning to read would provide benefit for instructors and researchers in terms of improving the methods to be used by these students in their education.

\section{Method}

\subsection{Research Model}

This research employed the screening model among the descriptive research models. The reading levels of the students with dyslexia were determined and analysed.

\subsection{Study Population}

The target population of the study consisted of 175 students found to have a risk of dyslexia, studying in the primary and secondary schools in the Kalecik District of Ankara, the capital of Turkey, selected through purposeful sampling. All the students who were found to have dyslexia in the district, were reached during the study. These students study in 11 different schools.

Those students included 26 Grade- 1 students, 30 Grade- 2 students, 24 Grade- 3 students, 25 Grade- 4 students, 31 Grade- 5 students, 23 Grade- 6 students, 13 Grade- 7 students and 12 Grade- 8 students. The frequency and percentage distributions of the study population are presented in Table 1.

Table 1. Distribution of students with dyslexia by grades

\begin{tabular}{lcc}
\hline Grade & f & \% \\
\hline Grade 1 & 26 & 14,85 \\
Grade 2 & 30 & 17,14 \\
Grade 3 & 24 & 13,71 \\
Grade 4 & 25 & 14,28 \\
Grade 5 & 31 & 17,71 \\
Grade 6 & 23 & 13,14 \\
Grade 7 & 13 & 7,42 \\
Grade 8 & 12 & 6,85 \\
TOTAL & $\mathbf{1 7 5}$ & $\mathbf{1 0 0}$ \\
\hline
\end{tabular}

The table shows that the distribution of students, except for those studying at Grade 7 and Grade 8 , is close to the grade levels. The decrease in number in the excepted grades, however, can be interpreted as a decrease resulting from the success of the reading training given.

\subsection{Data Collection Tools and Analysis}

In order to identify the reading levels of the students; the alphabet test, syllable list and "The Informal Reading Inventory" were employed as the measurement tools.

Alphabet Test: The test was prepared on the basis of the list of letters consisted of 29 letters in Turkish, in order to measure the letter recognition and phonetic knowledge of the students.

Syllable List: This constitutes a list of syllables consisting of two, three, four letters in order to measure the learning ability of the students (Eight items consisted of two syllables). 
Measuring Fluent Reading: The fluent reading skills were assessed using texts selected from Turkish textbooks, taught at every grade level and not yet seen by the student, in order to measure the fluent reading skill of the students.

During the assessment, The Informal Reading Inventory adapted into Turkish by Akyol (2006) was utilized. Adapted from Ekwall and Shanker (1988), this assessment tool measures the students' fluency reading levels, reading speed, error rates in reading, vocabulary and phonetic knowledge.

An expert opinion was taken on the validity of the tests used. The content of the measurement tool was reviewed, their eligibility for the study was analysed in terms of the content validity and the necessary arrangements were made in terms of language.

The Statistical Program for Social Sciences (SPSS 22) was used for data analysis. During the data collection, records were taken and the performances of the students were noted. The information gained was examined \& analysed and interpreted. The descriptive data were presented using frequency and percentage distributions.

\section{Results}

This study examines the reading levels of the students with dyslexia taking into consideration their grade levels.

Table 2. Students with dyslexia who cannot learn to read

\begin{tabular}{lcc}
\hline Reading Inability & f & \% \\
\hline Grade 1 & 6 & 3,42 \\
Grade 2 & 0 & 0 \\
Grade 3 & 0 & 0 \\
Grade 4 & 0 & 0 \\
Grade 5 & 4 & 2,28 \\
Grade 6 & 2 & 1,14 \\
Grade 7 & 0 & 0 \\
Grade 8 & 1 & 0,57 \\
TOTAL & $\mathbf{1 3}$ & $\mathbf{7 , 4 1}$ \\
\hline
\end{tabular}

The first table shows the students with dyslexia who can by no means recognize letters and learn to read by their grade levels. At all grade levels, a total of 13 students $(7,41 \%)$ were found not to learn to read. According to this, it can be said that the fact that students with dyslexia cannot associate the voices and letters and accordingly cannot learn to read constitutes a situation that is very rarely encountered. The distribution of students who cannot learn to read by their grades is shown in Figure 1. 


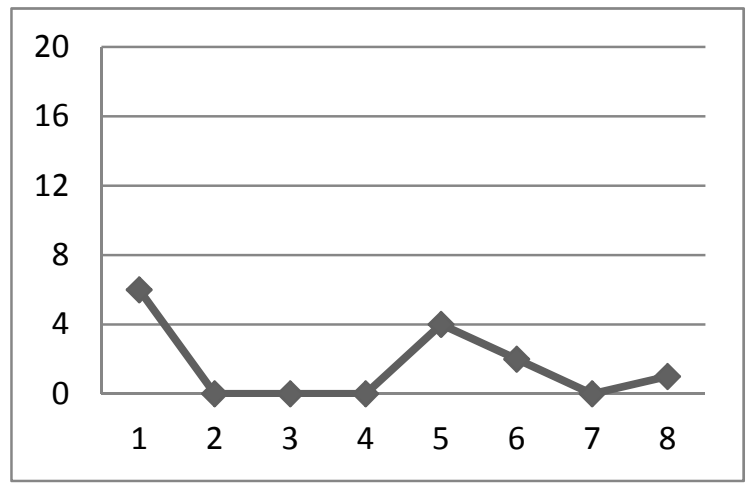

Figure 1. Distribution of students with dyslexia who cannot learn to read by their grades

According to the above figure, there are no dyslexic students who cannot learn reading at each of the grade level. It can be observed that such students exist particularly at Grade 1 and Grade 5 levels. The reason why they are more common in Grade 1 level lies behind the fact that, unlike many other countries, the reading instruction in Turkey starts at Grade 1 instead of the pre-school level. Accordingly, students experience problems in voice-letter coding in the year when they are acquainted with reading.

Table 3. Students with dyslexia who can only learn letters

\begin{tabular}{lcc}
\hline Inability to Learn Letters & f & \% \\
\hline Grade 1 & 6 & 3,42 \\
Grade 2 & 1 & 0,57 \\
Grade 3 & 0 & 0 \\
Grade 4 & 0 & 0 \\
Grade 5 & 1 & 0,57 \\
Grade 6 & 1 & 0,57 \\
Grade 7 & 0 & 0 \\
Grade 8 & 0 & 0 \\
TOTAL & 9 & $\mathbf{5 , 1 3}$ \\
\hline
\end{tabular}

Table 3 shows the students who grasp only the voice-letter coding but cannot move up to an upper step, namely spelling process. According to the table, 9 students (5.13\%) in total can only learn letters but cannot move up to the upper step, spelling process. The distribution of students who learn only letters and get stuck in the coding level by their grade levels is shown in Figure 2 


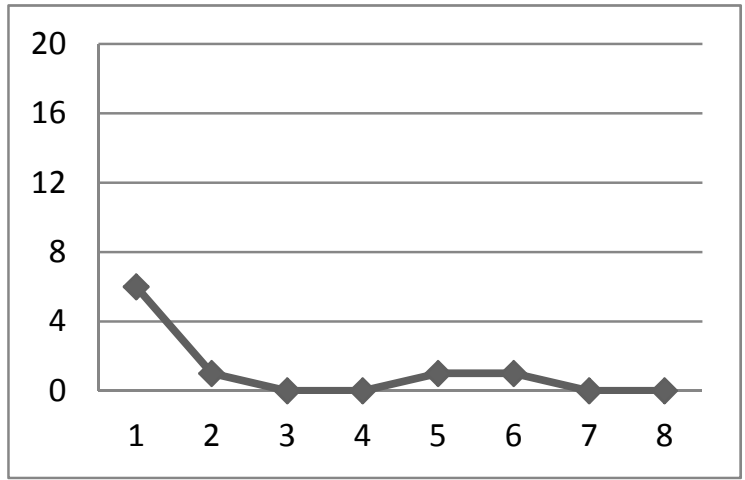

Figure 2. Distribution of students with dyslexia who can only learn letters by their grade levels

According to the figure, it is observed that these students generally exist at Grade 1. Given that the data were collected at the end of the school year, the fact that they still cannot pass this process at the end of the year they are acquainted with reading can be interpreted as a delay in learning to read. Because, at other grade levels, the number of students who got stuck at the level of letter learning, is relatively low.

Table 4. Student with dyslexia who can spell

\begin{tabular}{lll}
\hline Spelling & f & \% \\
\hline Grade 1 & 6 & 3,42 \\
Grade 2 & 12 & 6,85 \\
Grade 3 & 8 & 4,57 \\
Grade 4 & 5 & 2,85 \\
Grade 5 & 9 & 5,14 \\
Grade 6 & 9 & 5,14 \\
Grade 7 & 8 & 4,57 \\
Grade 8 & 5 & 2,85 \\
TOTAL & $\mathbf{6 2}$ & $\mathbf{3 5 , 3 9}$ \\
\hline
\end{tabular}

Table 4 shows the students who get stuck at the level of spelling during reading instruction. According to the table, a total of 62 students (35.39\%) have got stuck at the level of spelling and could not move up to the fluency level in reading. The distribution of these students by their grades is shown in Figure 3. 


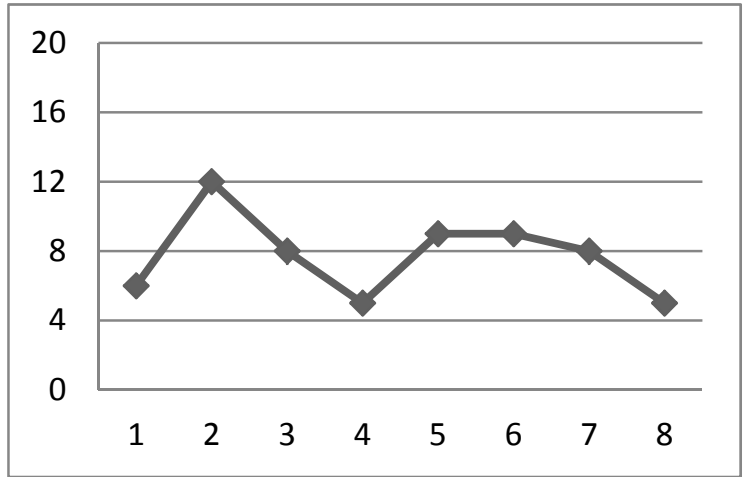

Figure 3. Distribution of students with dyslexia who got stuck at spelling level by their grades

According to the figure; although there is an increase in Grade 2 level among the grade levels, there are students with dyslexia who are stuck at the level of spelling in close proportions at other grade levels. The reason for the increase in Grade 2 level, however, can be interpreted as meaning that the fact that they began their reading education only a year ago, and can be attributed the slowness of the process of learning to read. Another important point is that such students significantly exist at every grade level until the end of the secondary school.

Table 5. Students with dyslexia who cannot read fluently

\begin{tabular}{lcc}
\hline Inability to Read Fluently & f & \% \\
\hline Grade 1 & 6 & 3,42 \\
Grade 2 & 16 & 9,14 \\
Grade 3 & 14 & 8 \\
Grade 4 & 20 & 11,42 \\
Grade 5 & 14 & 8 \\
Grade 6 & 10 & 5,71 \\
Grade 7 & 5 & 2,85 \\
Grade 8 & 6 & 3,42 \\
TOTAL & $\mathbf{9 1}$ & $\mathbf{5 1 , 6 9}$ \\
\hline
\end{tabular}

Table 5 shows the students who experience problems in fluent reading during reading instruction. According to the table, a total of 91 students $(51.69 \%)$ were included at this level. Their distribution by grade levels is shown in Figure 4. 


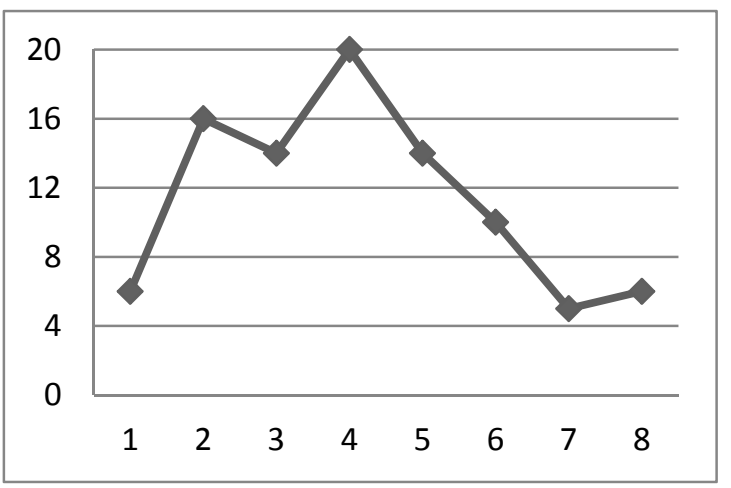

Figure 4. Distribution of students with dyslexia who have problems in fluent reading by grade levels

It is seen from the figure that the number of students with dyslexia who have problems in fluent reading decreases as the grade level increases. According to this figure, it can also be said that some students with dyslexia are able to overcome these problems over their education process. Another noteworthy data is that there is a significant number of students with dyslexia who have problems in fluent reading at every grade level, especially at the elementary school, except for the Grade 1. More than half of all students with dyslexia experience problems in fluency. The reason why this rate is low for the Grade 1 is both the fact that the students learn reading during that year and the low number of students reaching fluency level.

\section{Discussion}

This study aims to examine the reading levels of students with dyslexia, taking into account their grade levels. The ability of students to learn to read, to learn letters, to spell and to read fluently was examined on the basis of their age levels.

In the study, the number of students with dyslexia who cannot learn letters and cannot learn to read was found to be $(7 \%)$ whereas that of the students who only learn letters but cannot move up to the upper level, spelling, was found as (5\%), and their number is relatively low. These students are usually involved in these processes in the first years they start to receive reading instruction. The reason for this is that the individuals with dyslexia make a continuous progress in terms of reading within their own development (Francis, Shaywitz, Stuebing, Shaywitz \& Fletcher, 1996). In his study, Frith (1985) mentions that the students who have problems in reading experience less trouble during this period called logographic process. This may be interpreted as the fact that the students with dyslexia do not have problems in transiting from logographic process to the alphabetical process.

Another reason why the individuals with dyslexia do not have significant problems in the learning letters is that the Turkish language has a more linear phonetic encoding compared to the English.

Also, as suggested by Badian (1995), detecting the difficulties experienced in phonological coding in the year that reading education begins is an important harbinger of the word reading, fluent reading and writing problems that may be encountered in the following years. Therefore, it is advised that the instructors should put excessive emphasis on the difficulties in voice-letter coding.

Within the study, the students were seen to have difficulties in acquiring spelling skills. A significant number of students $(35 \%)$ experience problems in using phonological skills and can spell by having problems in recognizing the words. The students with dyslexia who experience intensive spelling problems were encountered at all grade levels. Agreeing with Bruck and Treiman (1990), the students with dyslexia show lower spelling skills compared to the normal readers. As supported by the studies of Treiman (1997), Cassar, Treiman, Moats, Pollo and Kessler (2005), the students with dyslexia learn to spell in the same way with normal readers but spell more slowly than they do, and the mistakes made in spelling and phonology is one of the most characteristic features of the students with dyslexia.

As a further conclusion of this study, more than half of the students confront us as individuals who have fluent reading problems. Fluent reading dyslexia is one of the most important problems of the individual, and in this study, this problem was particularly encountered in the students with dyslexia at every grade level. In their studies, Spinelli, De Luca, Di Filippo, Mancini, Martelli and Zoccolotti (2005) set forth that Italian students with dyslexia have problems in fluent reading depending on the length of the words. On the other hand, Suárez-Coalla, Ramos, Álvarez-Cañizo, and Cuetos (2014) indicate in their studies that the individuals with dyslexia experience 
problems in orthographic processes and this leads to fluent reading problems. However, Wimmer (1996) mentions in his study that the students with dyslexia no longer make phonological coding mistakes as of the end of Grade 4, but instead they read more slowly and make mistakes in writing. It is also observable in this study that the individuals with dyslexia have difficulty in overcoming especially the fluent reading problems.

\section{References}

Badian, N. A. (1995). Predicting reading ability over the long term: The changing roles of letter naming, phonological awareness and orthographic processing. Annals of Dyslexia, 45(1), 79-96. https://doi.org/10.1007/BF02648213

Balc1, E., \& Çayır, A. (2017). The Impact of Multiple Sensory Learning in Increasing the Phonological Awareness of the 4th Grade Student with Dyslexia. Journal of Mother Tongue Education, 5(2), 201-216.

Barton, S. (2002). Warninng Signs of Dyslexia. Retrieved from https://bartonreading.com

Bruck, M., \& Treiman, R. (1990). Phonological awareness and spelling in normal children and dyslexics: The case of initial consonant clusters. Journal of Experimental Child Psychology, 50(1), 156-178. https://doi.org/10.1016/0022-0965(90)90037-9

Cassar, M., Treiman, R., Moats, L., Pollo, T. C., \& Kessler, B. (2005). How do the spellings of children with dyslexia compare with those of nondyslexic children? Reading and Writing, 18(1), 27-49. https://doi.org/10.1007/s11145-004-2345-x

Ehri, L. C. (2005). Learning to read words: Theory, findings, and issues. Scientific Studies of Reading, 9(2), 167-188. https://doi.org/10.1207/s1532799xssr0902_4

Francis, D. J., Shaywitz, S. E., Stuebing, K. K., Shaywitz, B. A., \& Fletcher, J. M. (1996). Developmental lag versus deficit models of reading disability: A longitudinal, individual growth curves analysis. Journal of Educational Psychology, 88, 3-17. https://doi.org/10.1037/0022-0663.88.1.3

Frith, U. (1985). Beneath the surface of developmental dyslexia. In K. Patterson, J. Marshall, \& M. Coltheart (Eds.), Surface dyslexia (pp. 301-331). Londra: Erlbaum.

Shaywitz, S. (2003). Overcoming dyslexia: A new and complete science-based program for reading problems at any level. New York: Alfred A. Knopf.

Shaywitz, S. E. (1998). Current concepts: Dyslexia. The New England Journal Medicine, 338, 307-312. https://doi.org/10.1056/NEJM199801293380507

Spinelli, D., De Luca, M., Di Filippo, G., Mancini, M., Martelli, M., \& Zoccolotti, P. (2005). Length effect in word naming in reading: Role of reading experience and reading deficit in Italian readers. Developmental Neuropsychology, 27(2), 217-235. https://doi.org/10.1207/s15326942dn2702_2

Suárez-Coalla, P., Ramos, S., Álvarez-Cañizo, M., \& Cuetos, F. (2014). Orthographic learning in dyslexic Spanish children. Annals of Dyslexia, 64(2), 166-181. https://doi.org/10.1007/s11881-014-0092-5

Treiman, R. (1997). Spelling in normal children and dyslexics. Foundations of reading acquisition and dyslexia: Implications for early intervention, 191-218.

Wimmer, H. (1996). The early manifestation of developmental dyslexia: Evidence from German children. Reading and Writing, 8(2), 171-188. https://doi.org/10.1007/BF00555368

\section{Copyrights}

Copyright for this article is retained by the author(s), with first publication rights granted to the journal.

This is an open-access article distributed under the terms and conditions of the Creative Commons Attribution license (http://creativecommons.org/licenses/by/4.0/). 